\title{
Comparison of the Effect of Process Fluid Using the Test by Drilling a Constant Feed Force
}

Roman Licek, Miloslav Ledvina

Faculty of Mechanical Engineering, Department of Machining and Assembly, Technical University of Liberec, Studentská 2, 46117 Liberec, Czech Republic. E-mail: roman.licek@tul.cz, miloslav.ledvina@tul.cz

New types of process fluids is very broad. Drilling with constant feed force represents the experiment that follows different properties and effects in machining. The main aim of this scientific paper is to assess the speed of drilling holes by the drilling technology-constant feed force- with the drilling cutting tools made of uncoated high speed steel. Eleven different process fluids were compared used the during the experiment. There were compared eleven different process fluids. In the context of the thesis more process fluids from global suppliers have been tested. In the process of experiments there were used twist drills of high speed steel type HSS, ČSN 221121, ø 8 mm, without coating. Steel samples were $16 \mathrm{MnCr} 5$, according to EN 10084-94. During the experiment there was used drilling of holes by hand feed drill machine $\mathrm{V} 20$ that was modified with the mechanical switch and there was also stopwatch. Testing of process fluids in chip machining has been going on at the Department of machining and assembly of the Technical University of Liberec for many years.

Keywords: Machining, drilling, process fluids, time of drilling, chips

\section{Acknowledgement}

This paper is related to the investigation on the Specific University Research Projects, which are supported by the Ministry of Education (MSMT) of the Czech Republic.

\section{References}

[1] MACHADO, A.R., WALLBANK, J. (1997). The effect of extremely low lubricant volumes in machining. Wear 210:76-82.

[2] STOLARSKI, T., A. (1995). Tribology in Machine Design Handbook. Amsterdam: Elsevier Butterworth-Heinemann, 1995, 311 s. ISBN 0-7506- 3623-8.

[3] NESLUŠAN, M. aj. (2007). Experimentálne metody v triskovom obrábaní, Vydavatelstvo ŽU 2007, ISBN 97880-8070-711-8

[4] ČILliKOVÁ, M., PILC, J., MÁDL, J. (2008). Top trendy v obrábaní VI. Čast'- Procesné médiá, rok 2008,

[5] STřELCOVÁ, R. (2008). Řezné kapaliny a jejich uplatnění v moderní výrobě [Bakalářská práce]. Brno: Vysoké učení technické v Brně, Fakulta strojního inženýrství, 2008. 48s

[6] VASILKO, K. (2009). Teória a praxe trieskového obrábania, vyd. Fakulta výrobných technológií Technicke univerzity v Košiciach, so sídlom v Prešove, 2009, 532 s, ISBN: 978-80-553-0152-5

[7] LICEK, R., POPOV, A. (2012). Bergerhof, J., Návrh řezných podmínek a hodnocení vlivu procesních kapalin na tvorbu nárůstku u antikorozních ocelí. Strojírenská technologie. Rev. prof. Ing. Lukovics, CSc., prof. Dr. Ing. Holešovský. Vol. XVII, čj, 2012, number 5-6, page 317 - 326. ISSN 1211-4162.

[8] SANDVIK Coromant, Sandviken: Přiručka obráběni - kniha pro praktiky. Překlad M. Kudela. -. vyd. 1997.800 s. ISBN 91-972299-4-6.

[9] RÁZEK, V., MÁDL, J., KOUTNÝ, V. (2003). Metody zkoušení vlastností řezných kapalin. Strojírenská technologie. Rec. I. Kvasnička. roč. 8, záŕí 2003, č. 3. s. 21 - 24. ISSN 1211-4162.

[10] KREMANOVÁ, B., MÁDL, J., RÁZEK, V., KOUTNÝ, V. (2007). Vývoj nových technologických kapalin na bázi př́rodních surovin. Strojírenská technologie. Rec. I. Kvasnička. roč. 12, červen 2007, č. 2. s. 18 - 23. ISSN 1211-4162.

[11] SKLENIČKA J. (2009). Vliv geometrie břitu produktivnich vrtacich nastrojů na velikost řeznych sil, Diplomová práce, ZCU 2009

[12] POPOV, A., DUGIN, A. (2014). Study of reasons of increased active force using coolant with uncut chip thickness. International Journal of Advanced Manufacturing Technology. 2014. 70 (9-12), pp. 1555-1562.

[13] DUGIN, A., JERSÁK, J., POPOV, A. (2014). Method for determining of the anti-adhesion ability of cutting fluids. Manufacturing Technology. 2014, 14 (2), pp. 145-149 
[14] ŠULDOVÁ, P. Vliv úpravy hlavního břitu monolitního šroubovitého vrtáku na trvanlivost nástroje, Diplomová práce, Západočeská univrzita v Plzni.

[15] SLĂTINEANU, L., et al. (2016). Requirements statement in product design. IOP Conference Series: Materials Science and Engineering. Vol. 161. No. 1. IOP Publishing, 2016, 20th Innovative Manufacturing Engineering and Energy Conference (IManEE 2016.)

[16] MAJERIK, J., JAMRICHOVA, Z., DOBRIKOVA, M. (2012). The verification of axial forces and torques in drilling by the noncoated cutting tools and drills with the PVD TiN coating. In: Annals of DAAAM for 2012\&Proceedings of the 23rd International DAAAM World Symposium Intelligent Manufacturing \& Automation: Focus on Theory, Practice and Education: World Symposium, ISSN. 2012. p. 1726-9679.

[17] ANDRONOV, V. (2016). Sjednocení řezných kapalin ve ŠKODA AUTO a.s. 2016. Bachelor's Thesis. České vysoké učení technické v Praze. Vypočetní a informační centrum.

[18] V. MANOLE, L. SLĂTINEANU, S. C. OLARU, I. BEŞLiU, P. IUREA, A. GONÇALVES-COELHO, (2015). Results of an Experimental Research Concerning the Evaluation of Machinability by Drilling under Constant Feed Force, Applied Mechanics and Materials, Vols. 809-810, pp. 147-152, 2015

[19] NATH, Chandra; KURFESS, Thomas. (2016). Obstruction-type Chip Breakers for Controllable Chips and Improved Cooling/Lubrication During Drilling-A Feasibility Study. Procedia Manufacturing, 2016, 5: 375-385.

[20] JOKSCH, S. Evaluating the performance of water-misciblecutting fluids in tribotests and actual machining processes. Oemeta Chemische Werke GmbH, Uetersen, Germany. https://www.tapping-torque-test.com/files/5514/1233/8682/OEMETA_Evaluating_the_performance_of_water-miscible_cutting_fluid.pdf

[21] LICEK, R. (2017). Evaluation of Tribological Properties by Using Different Process Fluid by Test Ball on Disc. Manufacturing Technology, page 217 - 223, April 2017, Vol. 17, No. 2, ISSN 1213-2489.

[22] DAŇA, M., ZETEK, M., SCHORNÍK, V. (2017). Effect of Cutting Edge Geometry on Cutting Forces when Drilling Inconel 718. Manufacturing Technology, page 24-29, No. 1, volume 17, Year 2017, ISSN 1213-2489.

[23] MAŇKOVÁ, I., VRABEL', M., BEŇO, J., KOVAC, P., GOSTIMIROVIC, M. (2013). Application of Taguchi Method and Surface Response Methodology to Evaluate Of Mathematical Models to Chip Deformation when Drilling With Coated and Uncoated Twist Drills. Manufacturing Technology. Page 492-499, 2013, No. 4, volume 13, ISSN 1213-2489.

[24] LIU, D.F., Y.J. TANG, AND W.L. CONG. (2012). A review of mechanical drilling for composite laminates. Composite Structures, 2012. 94(4): p. 1265-1279.

[25] FARAZ, A., D. BIERMANN, K. WEINERT, (2009). Cutting edge rounding: An innovative tool wear criterion in drilling CFRP composite laminates. International Journal of Machine Tools \& Manufacture, 2009. 49(15): p. 1185-1196. 